\title{
Combination effects of reinforcing filler and impact modifier on the crystallization and toughening performances of poly(lactic acid)
}

\author{
N. Petchwattana ${ }^{1}$, P. Naknaen ${ }^{2}$, B. Narupai ${ }^{3}$ \\ ${ }^{1}$ Division of Polymer Materials Technology, Faculty of Agricultural Product Innovation and Technology, Srinakharinwirot \\ University, Ongkharak, 26120 Nakhon Nayok, Thailand \\ ${ }^{2}$ Division of Food Science and Nutrition, Faculty of Agricultural Product Innovation and Technology, Srinakharinwirot \\ University, Ongkharak, 26120 Nakhon Nayok, Thailand \\ ${ }^{3}$ Expert Centre of Innovative Materials, Thailand Institute of Scientific and Technological Research, Khlong Luang, \\ 12120 Pathumthani Thailand
}

Received 18 November 2019; accepted in revised form 21 February 2020

\begin{abstract}
In this research, poly(lactic acid) (PLA) was toughened and improved the crystallinity by rubber particles and inorganic filler. $\mathrm{CaCO}_{3}$ was employed as a filler and nucleating agent while poly(methyl methacrylate)-poly(butadiene-styrene) (MBS) core-shell impact modifier was added as a toughening agent. Overall, the enhancements of both the toughness and crystallization of PLA with $\mathrm{CaCO}_{3}$ and MBS were successfully achieved. The tensile modulus and strength of PLA increased with increasing $\mathrm{CaCO}_{3}$ content from 10 to $30 \mathrm{wt} \%$. However, they decreased slightly when $\mathrm{CaCO}_{3}$ loading reached $40 \mathrm{wt} \%$ due to particles agglomerations. With the addition of MBS rubber, the tensile modulus and strength of the PLA/CaCO 3 composites became lower than those observed for PLA/CaCO 3 composites due to the softening effect. Furthermore, the compositions with MBS showed superior toughness in terms of the tensile elongation at break and impact strength. $\mathrm{CaCO}_{3}$ nucleated the PLA crystal which reflected as the increase in the degree of crystallinity $\left(X_{\mathrm{c}}\right)$ by at least 2 times for all formulations studied. The crystallization half-time $\left(t_{1 / 2}\right)$ of PLA with $40 \mathrm{wt} \% \mathrm{CaCO}_{3}$ was dramatically reduced, from $26 \mathrm{~min}$, in neat PLA, to $0.9 \mathrm{~min}$. With the addition of MBS, it did at $2.7 \mathrm{~min}$ for the same $\mathrm{CaCO}_{3}$ content. The maximum increment of heat distortion temperature (HDT), around $8^{\circ} \mathrm{C}$, was found for the PLA with $20 \mathrm{wt} \% \mathrm{CaCO}_{3}$.
\end{abstract}

Keywords: polymer composites, impact modifier, nucleating agent, rubber toughening, crystallization

\section{Introduction}

Poly(lactic acid) (PLA) is widely known as a commercially available, compostable thermoplastic, with mechanical properties comparable to many petroleum-based plastics such as poly(ethylene terephthalate) (PET) and polystyrene (PS) [1-15]. However, the problems of brittleness, low impact resistance, and high material cost still limit the applications of PLA as fossil-based polymers substitutions.

In terms of toughness, many elastic materials were applied as a toughening agent in PLA. Although their achievements of the impact strength and elongation at break were reported. However, these were found to simultaneously sacrifice the crystallinity, strength and thermal stability of PLA [1-6, 12-15]. PLA has been toughened by several toughening agents; e.g., natural rubber, synthetic rubber, core-shell rubber (CSR) and other thermoplastics [1-2,11-15]. For instance, with the presence of thermoplastic copolyester elastomer (TPCE), the impact strength of PLA was increased by six-fold when TPCE was added at $30 \mathrm{wt} \%$ [12]. Blending PLA with $20 \mathrm{wt} \%$ epoxidized

$\overline{{ }^{*} \text { Corresponding author, e-mail: nawadon@g.swu.ac.th }}$

(C) BME-PT 
natural rubber (ENR) was found to increase the tensile elongation at break by three times while the impact strength increased by around five times [13]. Toughening PLA with $15 \mathrm{wt} \%$ poly(butyl acrylate) showed a drastic toughness improvement with the increased elongation at break from 4.52 to $174 \%$ while the impact strength increased from 2.13 to $47.02 \mathrm{MJ} / \mathrm{m}^{3}$ [14]. With the addition of ultrafine, fully vulcanized, acrylate rubber (UFPR), the tensile elongation at break dramatically increased from 3.46 to $198 \%$ and the impact strength increased by around five times at $10 \mathrm{wt} \%$ UFPR. The UFPR was found to induce numerous crazes as a mechanism of energy absorption [15]. In our previous work, we found that adding CSR to PLA/wood composites resulted in the toughness increment. Mechanical tests indicated that toughening PLA/wood flour composites with $5 \mathrm{wt} \%$ CSR significantly improved both the impact strength and the tensile elongation at break. Compared to other toughening systems, CSR seemed to be a more appropriate toughening agent for PLA and PLA composites. It required lower amounts than other toughening agents to improve the toughness of PLA [1-3, $6,15]$.

For the crystallinity and thermal stability point of view, previous literatures have indicated that adding inorganic fillers and natural fibers to PLA improved the degree of crystallinity, mechanical strength and thermal stability. However, the toughness reductions were also reported due to the brittle nature of PLA and the poor interfacial adhesion between PLA matrix and fillers. For example, the flexural strength and strain at break of PLA/CaCO 3 composites were found to be significantly reduced, especially when the filler loading was larger than $30 \mathrm{wt} \%$ [5]. The crystallization ability of PLA was found to significantly increase with the addition of talc. The authors concluded that in order to have PLA with good mechanical and thermal stability, both the presence of filler and PLA crystals are needed [17]. The tensile elongation at break and impact strength of the toughened PLA/rubber-wood sawdust composites were reduced with the wood flour loading due to their poor interfacial adhesion. With the addition of CSR, both the tensile elongation at break and impact strength were increased significantly [6]. With the presence of titanium dioxide, the elongation at break of PLA decreased by more than 1.5 times [7]. The problem of weak interfacial bonding is generally remedied by incorporating coupling agents, such as maleic anhydride-grafted PLA [8], silane coupling agent $[9,10]$ or epoxy-based coupling agent $[11]$. Although these chemicals have been reported to be effective as the interfacial adhesion promoters for PLA composites but they were less effective at high filler contents (more than $20 \mathrm{wt} \%$ ) [8-11]. Thus, the improvement of the PLA composite toughness still needs a more appropriate method in the case of highly filled PLA composites.

In this work, PLA was toughened and crystal nucleated simultaneously. $\mathrm{CaCO}_{3}$ was employed as a filler and nucleating agent while poly(methyl methacrylate)-poly(butadiene-styrene) (MBS) core-shell impact modifier was added as a toughening agent. Various tests were performed on $\mathrm{PLA} / \mathrm{CaCO}_{3}$ composites, with and without MBS, to evaluate the crystallization rate, mechanical performance and thermal stability.

\section{Materials and methods}

\subsection{Materials}

An injection grade of PLA (Ingeo ${ }^{\mathrm{TM}}$ Biopolymer 3001D, NatureWorks LLC, USA) was used as a polymer matrix. It has a density and melt flow index (MFI) of $1.23 \mathrm{~g} / \mathrm{cm}^{3}$ and $22 \mathrm{~g} / 10 \mathrm{~min}$, respectively. Fine particles of $\mathrm{CaCO}_{3}$ were added to PLA to reduce the raw material cost, increase the crystallization rate and improve the stiffness of PLA. It has a density and average particle size of $2.71 \mathrm{~g} / \mathrm{cm}^{3}$ and $5 \mu \mathrm{m}$ respectively. It was supplied by U\&V Holding Co., Ltd., Thailand. The MBS, supplied by Farto Square Co. $\mathrm{Ltd}$., was added to $\mathrm{PLA} / \mathrm{CaCO}_{3}$ composites to remedy the problem of brittleness. It has a bulk density and average particle size of $0.50 \mathrm{~g} / \mathrm{cm}^{3}$ and $500 \mathrm{~nm}$ respectively.

\subsection{Preparation of $\mathrm{PLA} / \mathrm{CaCO}_{3}$ composites and MBS toughened PLA/CaCO composites}

Each raw material was firstly dried in a vacuum oven at $65^{\circ} \mathrm{C}$ for $12 \mathrm{~h}$ to eliminate the inherent moisture. After that, the PLA was dry mixed with $10-40 \mathrm{wt} \%$ $\mathrm{CaCO}_{3}$. The $\mathrm{CaCO}_{3}$ compositions were then meltcompounded using a co-rotating, twin-screw extruder (CTE-D16L32, Charoen Tut Co. Ltd., Thailand) and pelletized to get the $\mathrm{PLA} / \mathrm{CaCO}_{3}$ composite pellets. The temperature profile of the extruder barrel was $160 / 175 / 185 / 190 / 185^{\circ} \mathrm{C}$. The PLA/CaCO 3 composite pellets were further dry- and then melt-extruded with $5 \mathrm{wt} \%$ MBS. Table 1 shows the composition 
Table 1. Blend formulations of the raw materials.

\begin{tabular}{|c|c|c|c|}
\hline Formulation code & $\begin{array}{c}\text { PLA } \\
{[\mathbf{w t} \%]}\end{array}$ & $\begin{array}{c}\mathbf{C a C O}_{\mathbf{3}} \\
{[\mathbf{w t} \mathbf{0}]}\end{array}$ & $\begin{array}{c}\text { MBS } \\
{[\mathbf{w t} \% \mathbf{0}]}\end{array}$ \\
\hline PLA & 100 & - & - \\
\hline PC10 & 90 & 10 & - \\
\hline PC20 & 80 & 20 & - \\
\hline PC30 & 70 & 30 & - \\
\hline PC40 & 60 & 40 & - \\
\hline PC10M & 85 & 10 & 5 \\
\hline PC20M & 75 & 20 & 5 \\
\hline PC30M & 65 & 30 & 5 \\
\hline PC40M & 55 & 40 & 5 \\
\hline
\end{tabular}

Table 2. Injection molding conditions.

\begin{tabular}{|l|c|}
\hline \multicolumn{1}{|c|}{ Designation } & Value \\
\hline Mold closing and clamping & $5 \mathrm{sec}$ \\
\hline Injection filling & $10 \mathrm{sec}$ \\
\hline Injection pressure holding & $15 \mathrm{sec}$ \\
\hline Cooling time & $60 \mathrm{sec}$ \\
\hline Mold opening, de-clamping and ejecting & $10 \mathrm{sec}$ \\
\hline Barrel temperature Zones 1 to 3 & $195 / 200 / 200^{\circ} \mathrm{C}$ \\
\hline Injection feed-forward pressures & $40-80 \mathrm{bar}$ \\
\hline Holding pressure & $30 \mathrm{bar}$ \\
\hline Mold clamping pressure & $70 \mathrm{bar}$ \\
\hline Ejector pressure & $30 \mathrm{bar}$ \\
\hline Mold temperature & $40^{\circ} \mathrm{C}$ \\
\hline
\end{tabular}

of the materials used in the current research. The pelletized formulations were all processed using an injection molding machine (INJ101T, Charoen Tut Co. Ltd., Thailand) to produce the test specimens. The injection molding conditions are shown in Table 2.

\subsection{Testing and characterizations}

Tensile tests were done at room temperature using a universal testing machine (INSTRON 5966, Instron Co., Ltd., USA) in accordance with ASTM D638. The crosshead speed was $50 \mathrm{~mm} / \mathrm{min}$ and the gauge length was set at $1 \mathrm{in}$. The Izod impact strength of each of the PLA/ $/ \mathrm{CaCO}_{3}$ and PLA/CaCO $3 / \mathrm{MBS}$ composites was determined using an Izod impact tester (BPI-25 COM, Zwick Roell, Germany) following the procedure described in ASTM D256. The mechanical test results reported were the average values of five tested specimens.

The impact fracture surfaces of the neat PLA, PLA/ $\mathrm{CaCO}_{3}$, and $\mathrm{PLA} / \mathrm{CaCO}_{3} / \mathrm{MBS}$ composites were investigated using a field emission scanning electron microscope (FE-SEM) (JSM IT500HR, JEOL, Japan) at an accelerating voltage of $1.0 \mathrm{kV}$. The test specimens were placed on aluminum stubs and coated with a thin layer of gold before the FE-SEM study. Differential scanning calorimetry (DSC) (DSC6000, PerkinElmer, Inc., USA) was performed on five to ten-milligram samples to observe the transition temperatures of the neat PLA, PLA/CaCO 3 and PLA/ $\mathrm{CaCO}_{3} / \mathrm{MBS}$ composites. The thermal scans started with heating from 0 to $200^{\circ} \mathrm{C}$ at a ramp rate of $5{ }^{\circ} \mathrm{C} / \mathrm{min}$ to remove the thermal history. The samples were held isothermally for $5 \mathrm{~min}$ at $200^{\circ} \mathrm{C}$ and then cooled down to $0^{\circ} \mathrm{C}$ at $5^{\circ} \mathrm{C} / \mathrm{min}$ and then held at $0^{\circ} \mathrm{C}$ for $5 \mathrm{~min}$. Finally, they were re-heated to $200^{\circ} \mathrm{C}$ at the same heating rate; the first cooling and second heating scans were reported. The degree of crystallinity $\left(X_{\mathrm{c}}\right)$ due to the second heating was calculated by Equation (1):

$X_{\mathrm{c}}=100 \cdot \frac{\Delta H_{\mathrm{M}}-\Delta H_{\mathrm{CC}}}{x_{\mathrm{p}} \cdot \Delta H^{0}}$

where $\Delta H_{\mathrm{M}}, \Delta H_{\mathrm{CC}}$ and $x_{\mathrm{p}}$ are the enthalpy of melting, enthalpy of the cold crystallization, and the weight fraction of the PLA in the composites respectively. These values were obtained from the area under the DSC second heating thermograms. $\Delta H^{0}$ is the heat of fusion obtained from the melting enthalpy of $100 \%$ crystalline PLA, which is $93 \mathrm{~J} / \mathrm{g}$ [15-17]. The crystallization half time $\left(t_{1 / 2}\right)$, at $100^{\circ} \mathrm{C}$, was determined using DSC isothermal scans. All the samples were heated from room temperature to $200^{\circ} \mathrm{C}$ at $5{ }^{\circ} \mathrm{C} / \mathrm{min}$ and then isothermally held at $200^{\circ} \mathrm{C}$ for $5 \mathrm{~min}$. They were cooled down to $100^{\circ} \mathrm{C}$ at $5^{\circ} \mathrm{C} / \mathrm{min}$ and held isothermally at this temperature until the crystallization was completed.

The service temperature of the PLA composites was measured using a heat distortion tester (HV-3000P3C, Gotech Testing Machines Inc., Republic of China) in accord with ASTM 648 with applied stress of $0.455 \mathrm{MPa}$. The measurements were conducted in silicone oil with a heating rate of $2{ }^{\circ} \mathrm{C} / \mathrm{min}$ until the test specimen deflected $0.25 \mathrm{~mm}$.

\section{Results and discussions}

\subsection{Mechanical properties and microscopic observations}

Figure 1 shows the modulus values of PLA/CaCO composites with and without MBS. It was found that adding $\mathrm{CaCO}_{3}$ into PLA leads to the increase of stiffness characterized by the Young's modulus by 15.0 , $39.6,54.2$ and $57.2 \%$ for $10,20,30$, and $40 \mathrm{wt} \%$ 
$\mathrm{CaCO}_{3}$ respectively. This indicated that $\mathrm{CaCO}_{3}$ played a significant role of PLA stiffness improvement and deformability restriction at all concentrations $[5,7,10]$. With the addition of MBS, the tensile moduli were reduced at all $\mathrm{CaCO}_{3}$ concentrations by $34.48,39.69,36.54$ and $25.19 \%$ for PLA with 10, 20, 30, and $40 \mathrm{wt} \% \mathrm{CaCO}_{3}$ respectively. The decreased

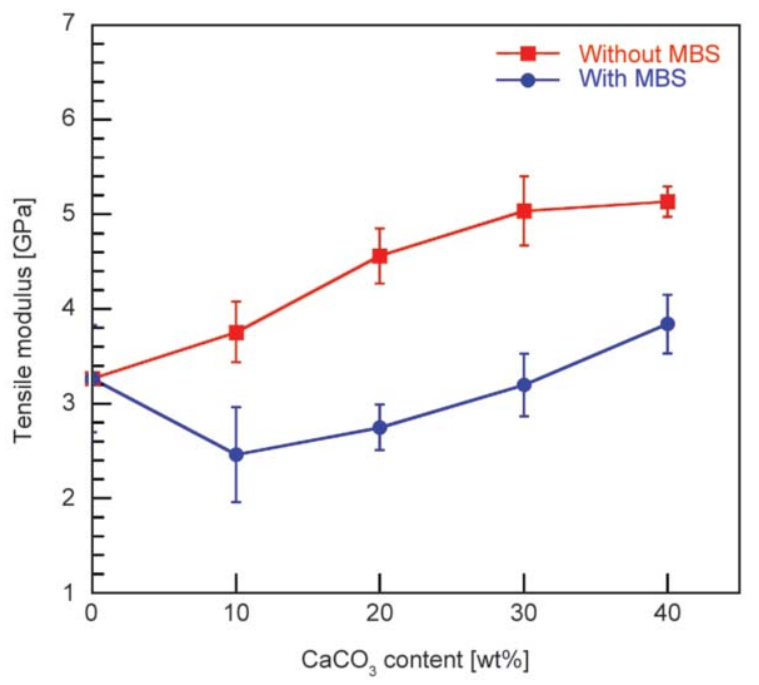

Figure 1. Tensile modulus of $\mathrm{PLA} / \mathrm{CaCO}_{3}$ composites with and without MBS. stiffness of PLA composites could be ascribed to the dispersed MBS particles which acted as a softener [18]. The tensile strengths of PLA filled with 10, 20, 30 and $40 \mathrm{wt} \% \mathrm{CaCO}_{3}$, with and without MBS, are graphically presented in Figure $2 . \mathrm{CaCO}_{3}$ exhibited its reinforcing effects on PLA with the increase of the tensile strength when it was added from 10$30 \mathrm{wt} \%$. We attributed the improved tensile strength to the good dispersion of $\mathrm{CaCO}_{3}$ which facilitated the $\mathrm{PLA}-\mathrm{CaCO}_{3}$ stress transfer at this loading range. However, there was a slight drop of the tensile strength when $\mathrm{CaCO}_{3}$ loading reached $40 \mathrm{wt} \%$ due to the agglomeration of the $\mathrm{CaCO}_{3}$ particles (Figure $2 \mathrm{~b}$ ). Modifying the $\mathrm{PLA} / \mathrm{CaCO}_{3}$ composite with MBS was found to soften PLA composites with the reduction of the tensile strength by around 9-21\% depending on $\mathrm{CaCO}_{3}$ concentration due to the softening effects of the MBS rubber. Interestingly, there was a drop in the tensile strength when PLA-CaCO loading reached $40 \mathrm{wt} \%$. This was due to the lack of $\mathrm{PLA}-\mathrm{CaCO}_{3}$ stress transfer from the agglomerations, as shown by the FE-SEM micrographs in Figure 2c. The results of the tensile modulus and tensile

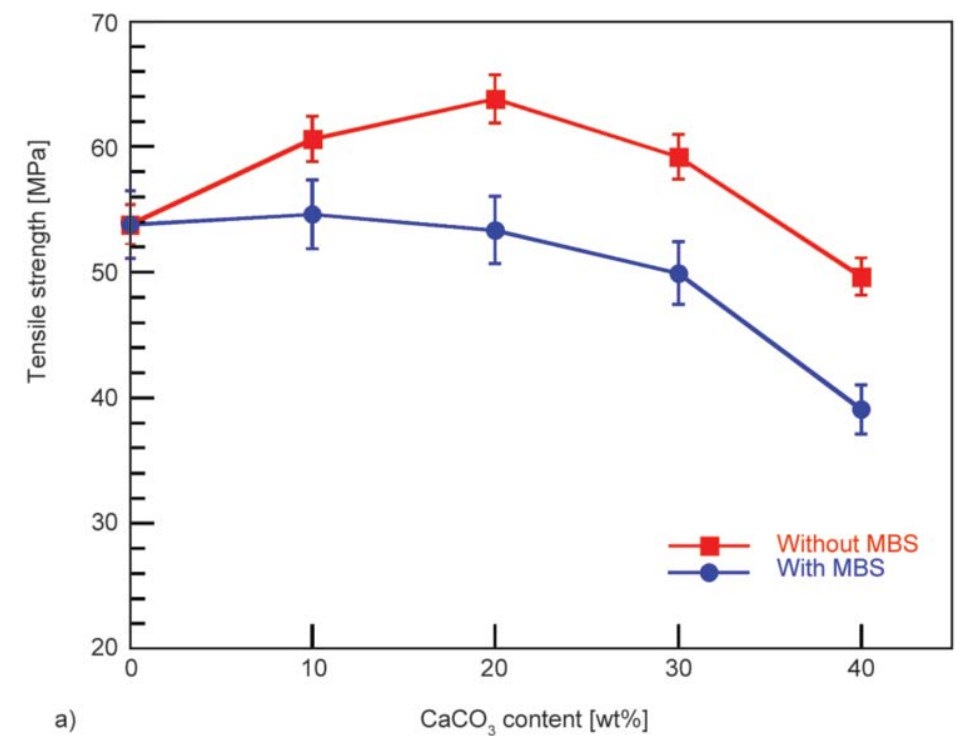

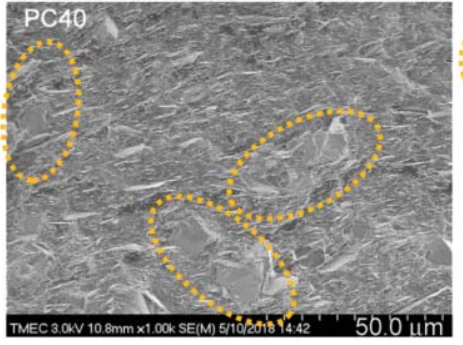

b)

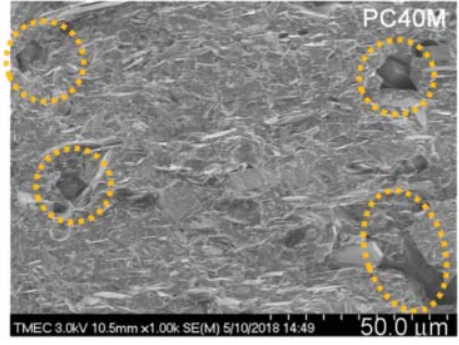

c)

Figure 2. Tensile strength of $\mathrm{PLA} / \mathrm{CaCO}_{3}$ composites with and without MBS. a) tensile strength of PLA/CaCO 3 composites, b) FE-SEM micrograph of PC40 and c) FE-SEM micrograph of PC40M. 
strength are in agreement with the previous reports. Kim et al. [19] found that the tensile modulus and strength of PLA increased with $\mathrm{CaCO}_{3}$ only for low loadings of 5-10 wt \%. Higher than these contents, their values dropped significantly. Kasuga et al. [5] showed that the increase of flexural strength of PLA was limited at $30 \mathrm{wt} \%$ of the vaterite form of $\mathrm{CaCO}_{3}$. Beyond this content, it reduced drastically. As shown in Figure 3, the tensile elongation at break of PLA was $7.1 \%$ and it increased to $29.5 \%$ with the addition of $5 \mathrm{wt} \%$ MBS. For PLA/ $\mathrm{CaCO}_{3}$ composites, the tensile elongation at break gradually reduced at all concentrations and reached the minimum value of $1.8 \%$ at $40 \mathrm{wt} \% \mathrm{CaCO}_{3}$. This is attributed to the restriction of PLA chain entanglements induced by the $\mathrm{CaCO}_{3}$ rigid particles during the tensile test $[1,20-21]$. This phenomenon has generally been found in semi-crystalline polymer/inorganic filler composites. Kim et al. [19] reported that the elongation at break of PLA reduced from 4 to $1.9 \%$ with the addition of $30 \mathrm{wt} \% \mathrm{CaCO}_{3}$. Osman et al. [22] showed that with the incorporation of only 0.2 vol $\% \mathrm{CaCO}_{3}$, the elongation at break of low-density polyethylene (LDPE) was dramatically reduced from 617 to $17 \%$. For PLA/ $\mathrm{CaCO}_{3}$ with MBS, the elongation at break of $\mathrm{PLA} / 10 \mathrm{wt} \% \mathrm{CaCO}_{3}$ was found to increase significantly from $7.1 \%$, in neat PLA, to nearly $24 \%$. The FE-SEM micrograph, in Figure 3c, shows the well-dispersed and embedded MBS within the PLA matrix. These were the main reason for the improvement of the elongation at break at $10 \mathrm{wt} \%$ $\mathrm{CaCO}_{3}$. Further addition of $\mathrm{CaCO}_{3}$ at $40 \mathrm{wt} \%$ in PLA/ $\mathrm{CaCO}_{3} / \mathrm{MBS}$ was found to linearly reduce the elongation at break down to $6.38 \%$ due to the agglomerations and PLA chain entanglement restrictions. Moreover, the poor interfacial adhesion between PLA and $\mathrm{CaCO}_{3}$ and the pulled-out $\mathrm{CaCO}_{3}$ particles which initiated the cracks [23] during the tension process were the additional causes of the elongation at break reductions. Our previous work on the toughening of
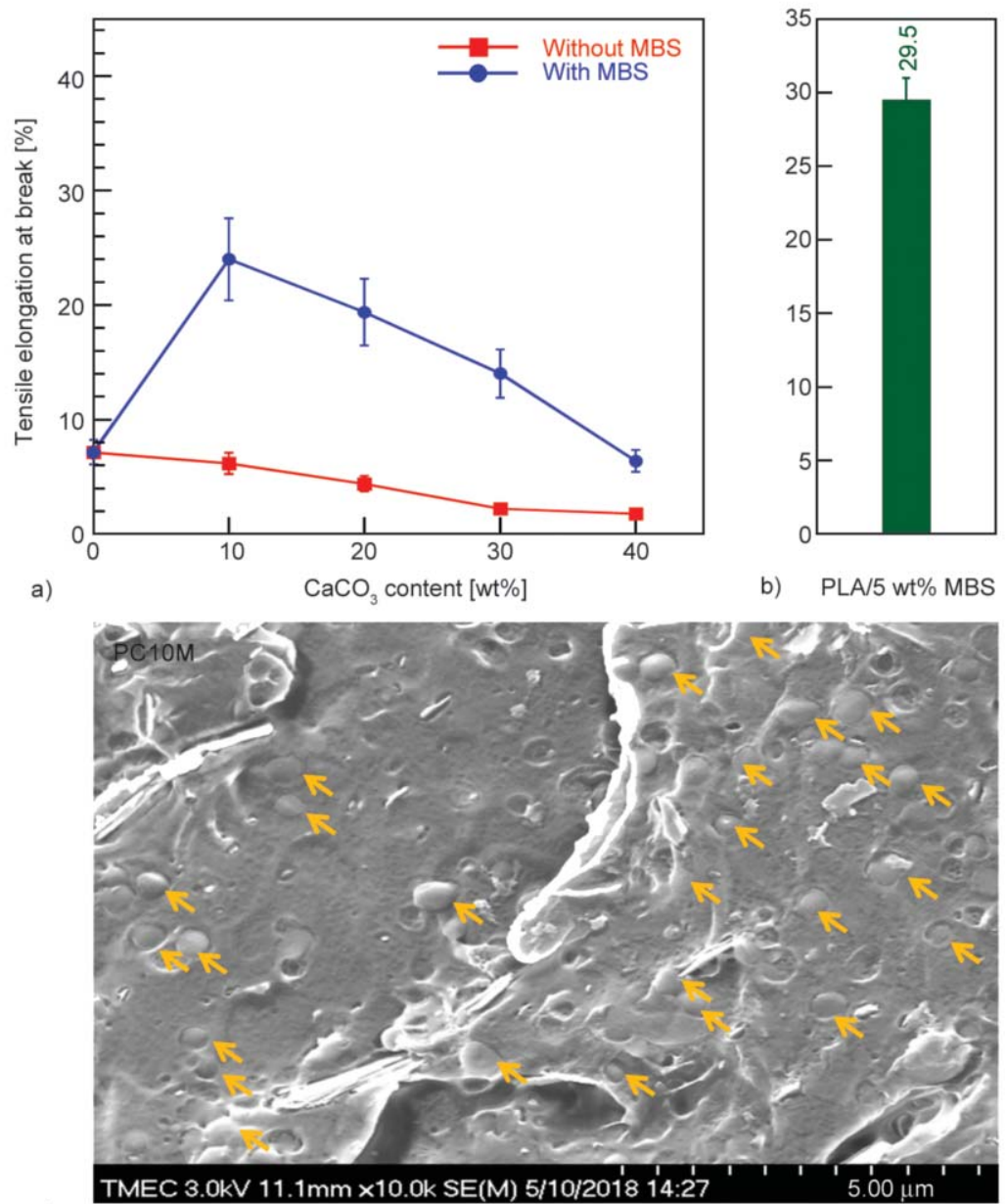

c)

Figure 3. Tensile elongation at break of $\mathrm{PLA} / \mathrm{CaCO}_{3}$ composites with and without MBS. a) Tensile elongation at break of $\mathrm{PLA} / \mathrm{CaCO}_{3}$ composites, $\mathrm{b}$ ) tensile elongation at break of PLA $/ 5 \mathrm{wt} \% \mathrm{MBS}$ and c) dispersion of MBS in PLA matrix (PC10M). 

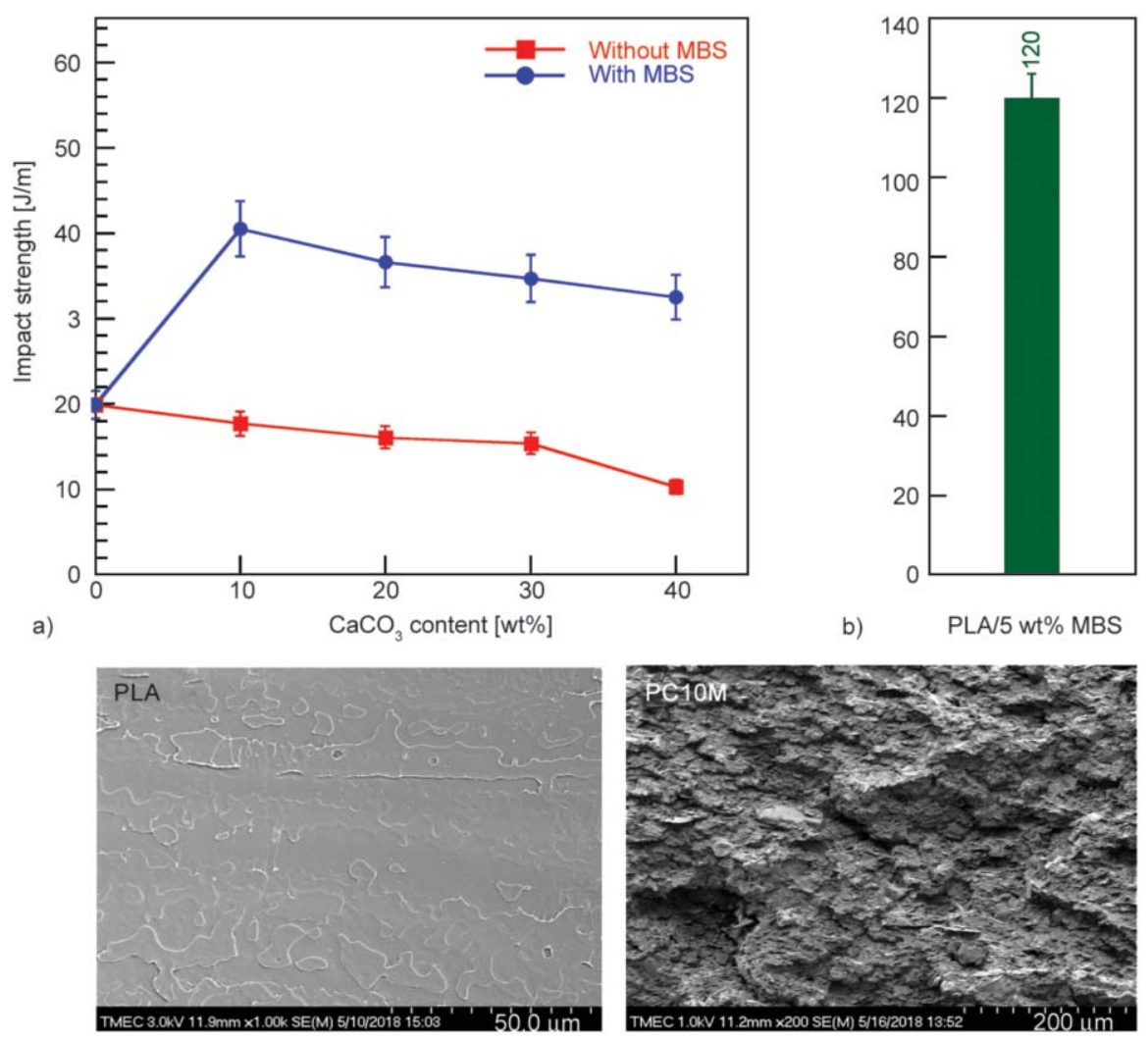

c)

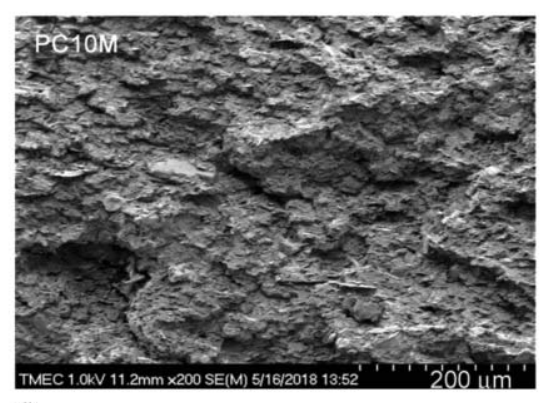

d)

Figure 4. Impact strength of $\mathrm{PLA} / \mathrm{CaCO}_{3}$ composites with and without MBS. a) Impact strength of PLA/CaCO 3 composites, b) impact strength of PLA $/ 5 \mathrm{wt} \% \mathrm{MBS}, \mathrm{c}$ ) impact fracture surface of neat PLA and d) impact fracture surface of PC10M.

PLA/wood composites indicated that adding the acrylic impact modifier played an important role in the elongation at break improvement. FE-SEM micrographs of PLA/ acrylic impact modifier indicated some plastic deformations induced by the acrylic impact modifier together with the cavitations. These were the critical parameters for the toughness improvement for PLA/wood composites [6].

As shown in Figure 4a, the impact strength of PLA was around $20 \mathrm{~J} / \mathrm{m}$ and the PLA $/ \mathrm{CaCO}_{3}$ composites, with and without MBS, behaved similarly to the tensile elongation at break. In Figure $4 b$, the PLA/MBS showed the impact strength of $120 \mathrm{~J} / \mathrm{m}$. For the PLA/ $\mathrm{CaCO}_{3}$ composites, the impact strength linearly decreased with increasing $\mathrm{CaCO}_{3}$ filler especially at $40 \mathrm{wt} \%$. For the composites with MBS, the impact strength was found to increase by around two times for all $\mathrm{CaCO}_{3}$ loading. The inserted FE-SEM images in Figure $4 \mathrm{c}$ and $4 \mathrm{~d}$ indicated some morphological differences between the neat PLA and PLA/ $\mathrm{CaCO}_{3} /$ MBS composites. Neat PLA fractured with a very smooth surface which allowed the crack to propagate rapidly; low impact energy was required in this case.
In Figure 4d, the composite with MBS (PC10M) showed a rough fracture surface which indicated that more energy was required to propagate the crack and break the specimen $[1,6,15]$. This result is in agreement with numerous reports. Battegazzore et al. [24] toughened PLA/ cotton fabric composites with polyhydroxybutyrate (PHB) and found the highest Charpy impact strength of $54.5 \mathrm{~kJ} / \mathrm{m}^{2}$. With the addition of the epoxidized natural rubber (ENR), the toughness of PLA/talc composites significantly increased more than ten times due to ENR concentration. The authors suggested that the ENR facilitated the mobility of PLA chains which allowed the PLA/talc/ENR composites to deform with difficulty during applied impact force [25].

\subsection{Crystallization behavior}

Figure 5 illustrates the DSC thermograms of the neat PLA and its composites with and without MBS obtained from the second heating scan. Further peak identifications and calculations are listed in Table 3. Neat PLA showed a $T_{\mathrm{g}}$ value of $61.9^{\circ} \mathrm{C}$. The incorporation of $\mathrm{CaCO}_{3}$ slightly changed the $T_{\mathrm{g}}$ of PLA 

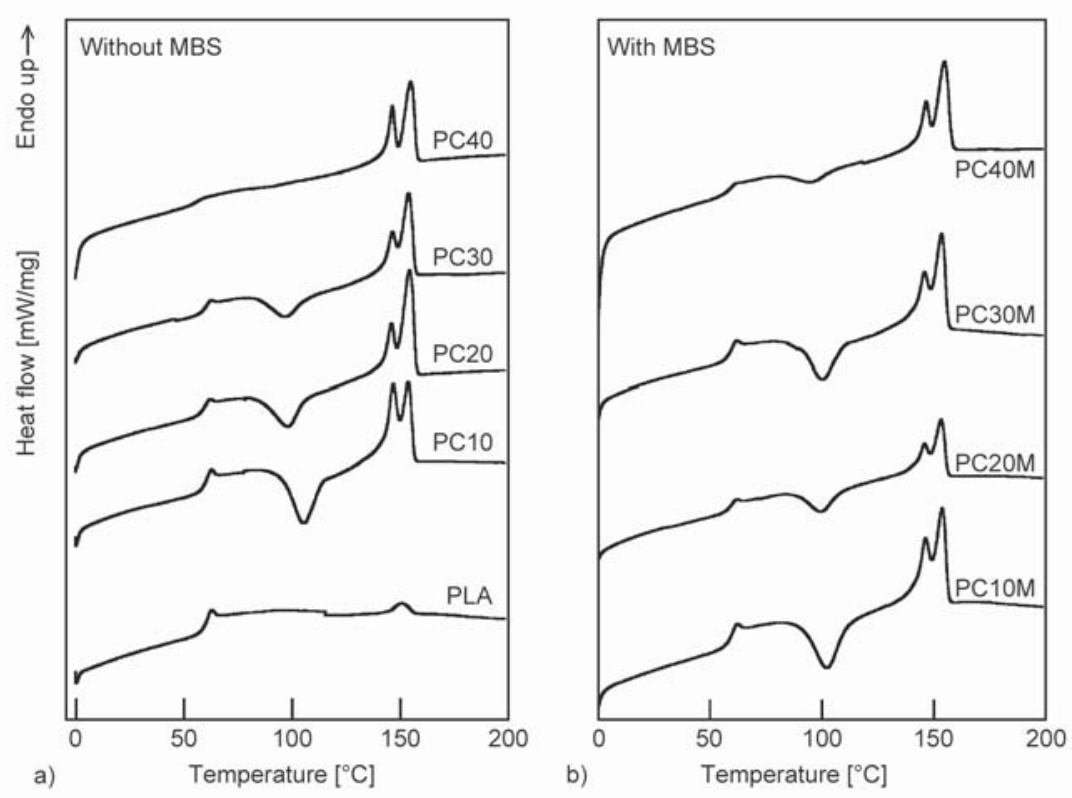

Figure 5. DSC second heating thermograms of the $\mathrm{PLA} / \mathrm{CaCO}_{3}$ composites a) without MBS and b) with MBS.

by around $1-2{ }^{\circ} \mathrm{C}$ for all compositions. The maximum $T_{\mathrm{g}}$ of 62.8 and $62.4^{\circ} \mathrm{C}$ was observed in PC40 and $\mathrm{PC} 40 \mathrm{M}$ respectively. This was generally reported in other nucleated PLA systems $[17,26]$.

The crystallization temperature is a parameter related to the crystallization rate of the polymer [27]. With the addition of a nucleating agent, a decrease of crystallization temperature upon cooling $\left(T_{\mathrm{co}}\right)$ refers to a slower crystallization rate whereas a decrease of crystallization temperature upon heating $\left(T_{\mathrm{cc}}\right)$ indicates a faster crystallization rate [27, 28]. As shown in Figure 5 and Table 3, the $T_{\mathrm{cc}}$ of PLA composites was significantly reduced by around $20^{\circ} \mathrm{C}$ for all $\mathrm{PLA} / \mathrm{CaCO}_{3}$ and $\mathrm{PLA} / \mathrm{MBS} / \mathrm{CaCO}_{3}$ compositions. This is attributed to the crystallization

Table 3. Thermal transition temperatures and degree of crystallinity of $\mathrm{PLA} / \mathrm{CaCO}_{3}$ composites with and without MBS obtained from the cooling and $2^{\text {nd }}$ heating thermograms.

\begin{tabular}{|l|c|c|c|c|c|c|}
\hline Formulation & $\begin{array}{c}\boldsymbol{T}_{\mathbf{c o}} \\
{\left[{ }^{\circ} \mathbf{C}\right]^{*}}\end{array}$ & $\begin{array}{c}\boldsymbol{T}_{\mathbf{g}} \\
{\left[{ }^{\circ} \mathbf{C}\right]^{* * *}}\end{array}$ & $\begin{array}{c}\mathbf{T}_{\mathbf{c c}} \\
{\left[{ }^{\circ} \mathbf{C}\right]^{* * *}}\end{array}$ & $\begin{array}{c}\boldsymbol{T}_{\mathbf{m}_{1}} \\
{\left[{ }^{\circ} \mathbf{C}^{* * *}\right.}\end{array}$ & $\begin{array}{c}\boldsymbol{T}_{\mathbf{m}_{2}} \\
{\left[{ }^{\circ} \mathbf{C}^{* * *}\right.}\end{array}$ & $\begin{array}{c}\boldsymbol{X}_{\mathbf{c}} \\
{\left[\mathbf{\%}^{* * *}\right.}\end{array}$ \\
\hline PLA $]^{*}$ & n.d. & 61.2 & 120 & 150 & n.d. & 8.30 \\
\hline PC10 & 92.8 & 61.9 & 105 & 146 & 153 & 21.7 \\
\hline PC20 & 95.2 & 62.2 & 97.0 & 145 & 154 & 22.8 \\
\hline PC40 & 97.1 & 62.0 & 97.2 & 145 & 153 & 23.8 \\
\hline PC10M & 99.3 & 62.8 & 96.4 & 143 & 152 & 24.3 \\
\hline PC20M & 95.9 & 61.9 & 102 & 145 & 153 & 20.5 \\
\hline PC30M & 95.8 & 61.3 & 99.6 & 145 & 153 & 18.6 \\
\hline PC40M & 95.9 & 61.3 & 100 & 145 & 153 & 20.1 \\
\hline
\end{tabular}

* Obtained from the cooling thermogram

${ }^{* *}$ Obtained from the $2^{\text {nd }}$ heating thermogram

n.d. $=$ no crystallization or melting peaks were detected acceleration of the PLA by $\mathrm{CaCO}_{3}$ and provided a benefit for the injection molding process. This crystallization enhancement was mainly due to the poor interfacial morphology of $\mathrm{CaCO}_{3}$ in the PLA matrix as illustrated in Figure 6. The poor interfacial adhesion and voids around $\mathrm{CaCO}_{3}$ particles were observed on both PLA composites with and without MBS. These incompatible phases induced thermal insulation zone which reduced the heat transfer from the PLA matrix to $\mathrm{CaCO}_{3}$ particles and the temperature of the $\mathrm{CaCO}_{3}$ particles remained lower than that of the PLA matrix. These cold spots turned into the crystal nuclei and then the PLA chains around these nuclei started to form crystals [27-31]. This made the whole PLA samples were crystallized at lower temperature. In comparison, the $\mathrm{PLA} / \mathrm{CaCO}_{3}$ composites showed slight-lower $T_{\mathrm{cc}}$ than that observed in PLA/ $\mathrm{CaCO}_{3} / \mathrm{MBS}$ composites with the same $\mathrm{CaCO}_{3}$ content. This was due to the crystallization obstruction induced by MBS, as we previously reported $[6,31]$. For $T_{\mathrm{m}}$, single melting endotherm was observed at $150{ }^{\circ} \mathrm{C}$ in neat PLA. The addition of $\mathrm{CaCO}_{3}$ did not significantly shift the $T_{\mathrm{m}}$ of PLA. With $\mathrm{CaCO}_{3}$ filler, the $T_{\mathrm{m}}$ split into two peaks due to the less-perfect crystals formed by cold crystallization during the reheating process $[32,33]$. For the polymer processing point of view, the $T_{\mathrm{cc}}$ data is usually used to describe the crystallinity data of the plastic injection molding process, annealing process or increase in the dimensional stability of plastic products. A lower $T_{\mathrm{cc}}$ indicates that less energy is required for the injection 


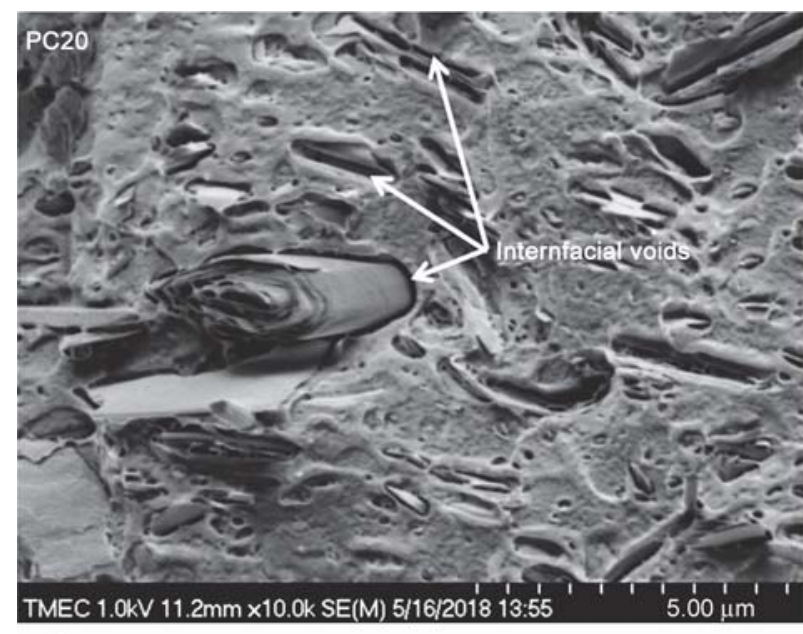

a)

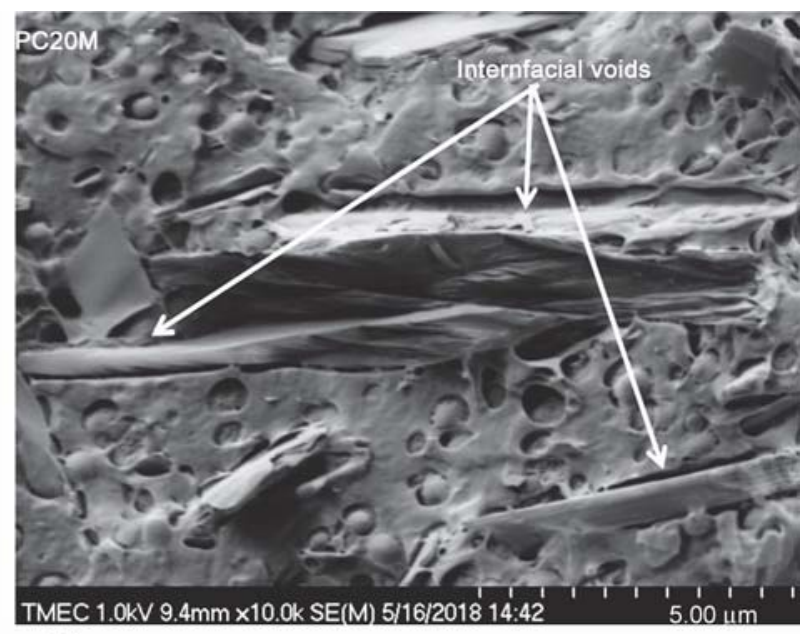

Figure 6. Fractured surfaces of the composites with $20 \mathrm{wt} \% \mathrm{CaCO}_{3}$ indicating the interfacial voids and cold spots of nucleations. a) PC20 and b) PC20M.

process since a lower temperature can be used [34, 35].

Figure 7 shows the cooling curves of PLA and its composites with and without MBS. For neat PLA, no crystallization peak was observed under this cooling condition. With the presence of $\mathrm{CaCO}_{3}$, a single peak was observed at all loadings and the $T_{\mathrm{co}}$ tended to increase slightly with increasing $\mathrm{CaCO}_{3}$ concentrations. For the $\mathrm{PLA} / \mathrm{CaCO}_{3}$ with $\mathrm{MBS}$, no significant change in $T_{\text {co }}$ was detected. These confirmed the nucleating ability of $\mathrm{CaCO}_{3}$ for PLA crystallization and that obstruction was done by the MBS.

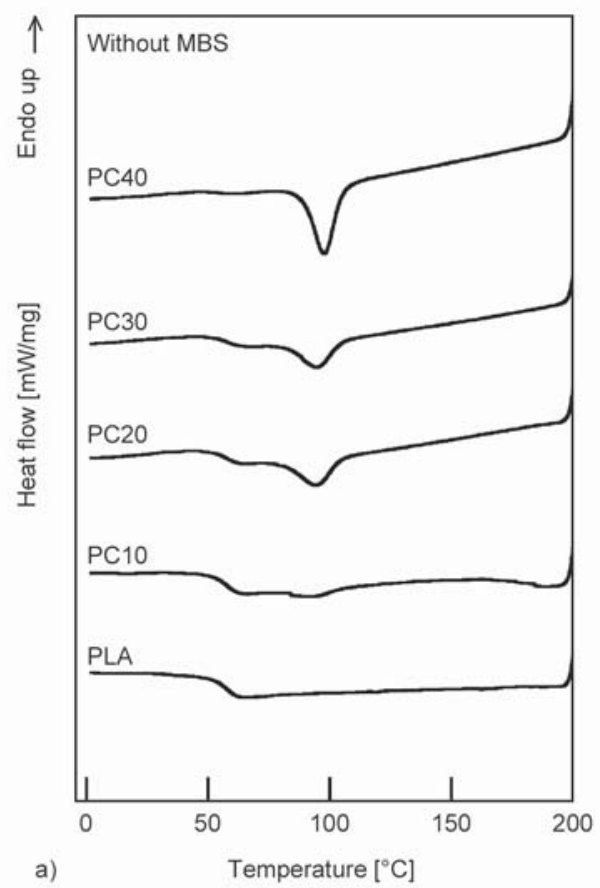

Table 3 shows some significant improvements in the degree of crystallinity $\left(X_{\mathrm{c}}\right)$ of the PLA composites with the addition of $\mathrm{CaCO}_{3}$, which were calculated following Equation (1). The $X_{\mathrm{c}}$ increased significantly since $\mathrm{CaCO}_{3}$ was added at $10 \mathrm{wt} \%$ and then slightly increased with further addition of the filler. The $\mathrm{CaCO}_{3}$ particles are suggested to have promoted the crystal formation as well as accelerated the crystallization rate in PLA via the mechanism described above. This is similar to the results reported by Liang et al. [32]. With the addition of nano $\mathrm{CaCO}_{3}$, the $X_{\mathrm{c}}$ of PLA increased from around 5 to $35 \%$ with only

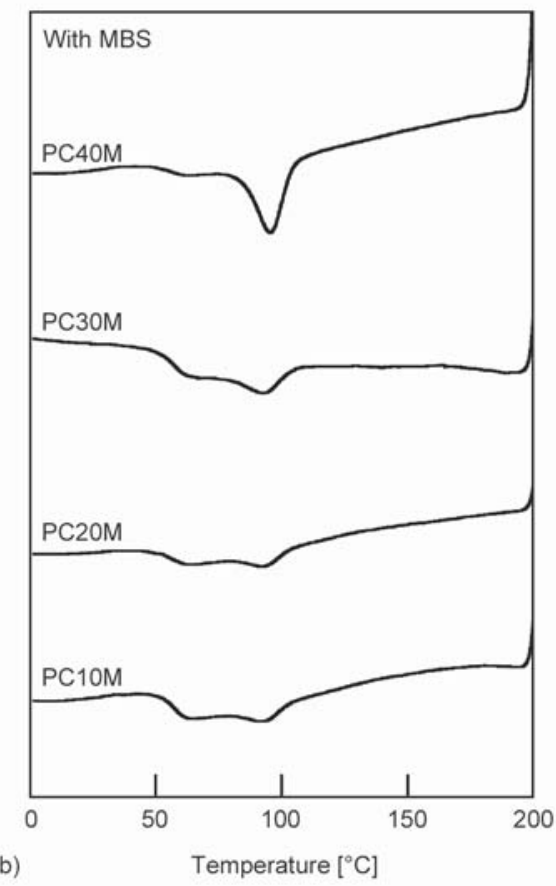

b)
Figure 7. DSC cooling thermograms of the PLA/CaCO 3 composites a) without MBS and b) with MBS. 
$2 \mathrm{wt} \%$ filler added while the $T_{\mathrm{c}}$ reduced by around $10{ }^{\circ} \mathrm{C}$. Our previous work indicated that with the addition of talc, the $X_{\mathrm{c}}$ of PLA increased from 3.6 to $30.9 \%$ [33]. Xia et al. [36] found that adding flax fiber to PLA increased the $X_{\mathrm{c}}$ by two times. Further observation indicated that the flax fiber reduced the crystal size of PLA and induced the formation of $\alpha$-form crystals.

As shown in Figure 8, the $t_{1 / 2}$ values of PLA crystallized at $100^{\circ} \mathrm{C}$ and the DSC isothermal peaks were dramatically reduced, from 26 to $0.9 \mathrm{~min}$, with the addition of $40 \mathrm{wt} \% \mathrm{CaCO}_{3}$. For the composites with MBS, it decreased to $2.7 \mathrm{~min}$ at the same $\mathrm{CaCO}_{3}$ loading. Technically, the crystallization rate is related to the free enthalpy of the crystal nuclei formation $[27,35,37]$. In this case, neat PLA had a high free enthalpy resulted in the PLA with a very slow crystallization rate. Adding $\mathrm{CaCO}_{3}$ resulted in the decrease of this free enthalpy and enhanced the crystal nucleation at this tested temperature. These results are also similar to those observed in the previous literatures. The $t_{1 / 2}$ of the PLA/talc composites was reduced from 35 min down to 4 min with the addition of $10 \mathrm{wt} \%$ talc [27] while modifying PLA with dimethylbenzylidene sorbitol was found to reduce the crystallization time $\left(t_{\mathrm{c}}\right)$ from more than 40 to less than $5 \mathrm{~min}$ at the crystallization temperature of $100^{\circ} \mathrm{C}[4]$.

\subsection{Heat distortion temperature (HDT)}

As shown in Figure 9, neat PLA exhibited the HDT value of $53.8^{\circ} \mathrm{C}$, and all the formulations showed higher HDT values than that observed in neat PLA. In PLA composites, it increased to 57.7, 61.3, 59.1 and $54.1^{\circ} \mathrm{C}$ for PLA with $10,20,30$ and $40 \mathrm{wt} \%$ $\mathrm{CaCO}_{3}$ respectively. With the MBS toughening, it changed to $55.4,56.9,55.4$, and $51.8^{\circ} \mathrm{C}$ for PLA with $10,20,30$ and $40 \mathrm{wt} \% \mathrm{CaCO}_{3}$ respectively. These increments were mainly due to the increased $X_{\mathrm{c}}$ and the reinforcement effect provided by the

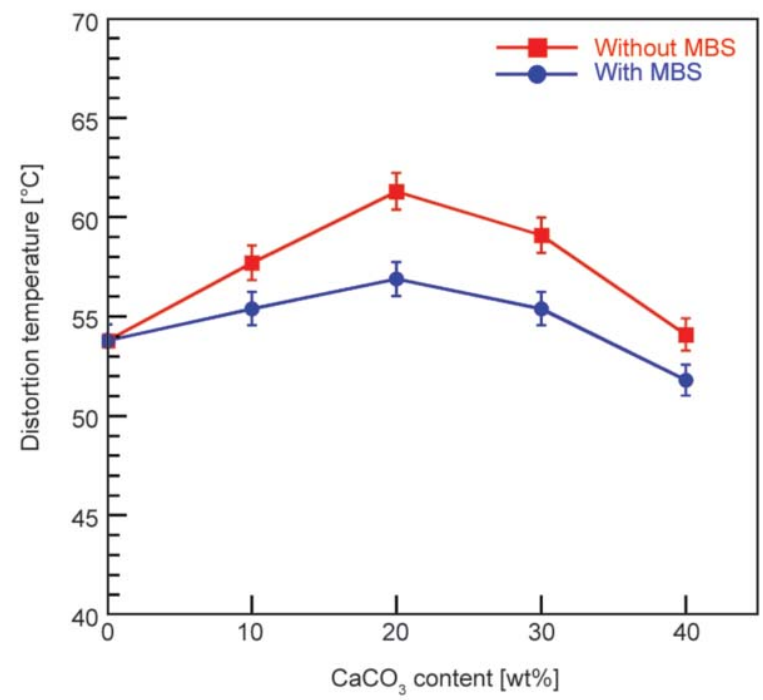

Figure 9. $\mathrm{HDT}$ of the $\mathrm{PLA} / \mathrm{CaCO}_{3}$ composites with and without MBS.

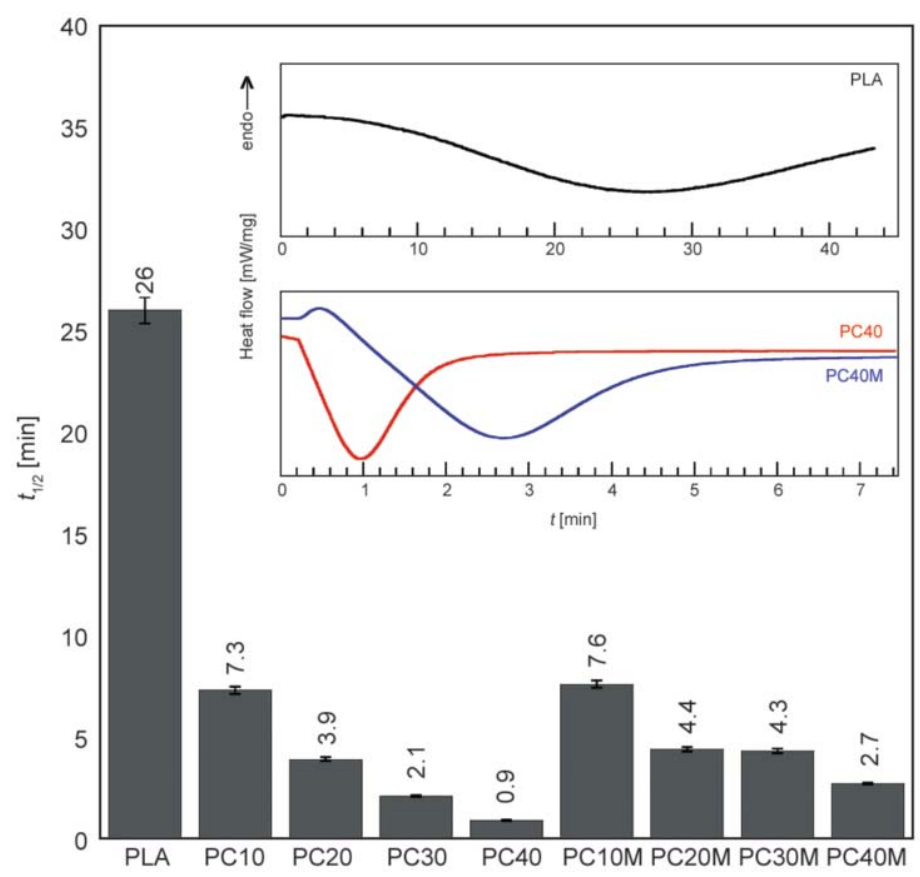

Figure 8. Crystallization half time $\left(t_{1 / 2}\right)$ at $100{ }^{\circ} \mathrm{C}$ of the PLA and $\mathrm{PLA} / \mathrm{CaCO}_{3}$ composites with and without $\mathrm{MBS}$ obtained from the isothermal DSC thermogram enclosed with the DSC isothermal curves. 
$\mathrm{CaCO}_{3}$ particles $[33,37]$. Although the addition of $\mathrm{CaCO}_{3}$ improved the HDT value of PLA, this still limits the use of PLA for high-temperature applications such as microwavable food packaging, automotive interior part or outdoor furniture. For the high heat resistance PLA product manufacturing, longer injection molding cycle time, higher mold temperature or annealing process are recommended for these formulations.

\section{Conclusions}

In this research, PLA was modified by a toughening agent and a reinforcing filler. Overall, the enhancements of both the toughness and crystallization of PLA with $\mathrm{CaCO}_{3}$ and MBS were successfully observed. The $X_{\mathrm{c}}$, HDT, tensile strength and impact strength were all increased. Moreover, $t_{1 / 2}$ significantly reduced from 26 to 0.9 and $2.7 \mathrm{~min}$ for PC40 and $\mathrm{PC} 40 \mathrm{M}$ respectively. The maximum increment of HDT, by around $8{ }^{\circ} \mathrm{C}$, was found for the PLA with $20 \mathrm{wt} \% \mathrm{CaCO}_{3}$. However, this still limits the use of PLA for high-temperature application. For the high heat resistance PLA manufacturing, longer injection molding cycle time, higher mold temperature or annealing process are recommended for these formulations.

\section{Acknowledgements}

The authors would like to acknowledge the research grant supported by Srinakharinwirot University (Contract no. 030/2560). Thanks are extended to Mr. Kittisak Phromsuk, Miss Chantaka Nasom, and Mr. Tantai Hongsuwan for their assistance.

\section{References}

[1] Petchwattana N., Sanetuntikul J., Narupai B.: Plasticization of biodegradable poly(lactic acid) by different triglyceride molecular sizes: A comparative study with glycerol. Journal of Polymers and the Environment, 26, 1160-1168 (2018).

https://doi.org/10.1007/s10924-017-1012-7

[2] Deng Y., Yu C., Wongwiwattana P., Thomas N-L.: Optimising ductility of poly(lactic acid)/poly(butylene adipate-co-terephthalate) blends through $c o$-continuous phase morphology. Journal of Polymers and the Environment, 26, 3802-3816 (2018).

https://doi.org/10.1007/s10924-018-1256-x
[3] Petchwattana N., Naknaen P., Narupai B.: A circular economy use of waste wood sawdust for wood plastic composite production: Effect of bio-plasticiser on the toughness. International Journal of Sustainable Engineering, in press (2019).

https://doi.org/10.1080/19397038.2019.1688422

[4] Petchwattana N., Naknaen P., Sanetuntikul J., Narupai B.: Crystallisation behaviour and transparency of poly (lactic acid) nucleated with dimethylbenzylidene sorbitol. Plastics, Rubber and Composites, 47, 147-155 (2018).

https://doi.org/10.1080/14658011.2018.1447338

[5] Kasuga T., Maeda H., Kato K., Nogami M., Hata K-I., Ueda M.: Preparation of poly(lactic acid) composites containing calcium carbonate (vaterite). Biomaterials, 24, 3247-3253 (2003). https://doi.org/10.1016/S0142-9612(03)00190-X

[6] Petchwattana N., Covavisaruch S.: Mechanical and morphological properties of wood plastic biocomposites prepared from toughened poly(lactic acid) and rubber wood sawdust (Hevea brasiliensis). Journal of Bionic Engineering, 11, 630-637 (2014). https://doi.org/10.1016/S1672-6529(14)60074-3

[7] Fonseca C., Ochoa A., Ulloa M. T., Alvarez E., Canales D., Zapata P. A.: Poly(lactic acid) $/ \mathrm{TiO}_{2}$ nanocomposites as alternative biocidal and antifungal materials. Materials Science and Engineering: C, 57, 314-320 (2015). https://doi.org/10.1016/j.msec.2015.07.069

[8] Dzul-Cervantes M., Herrera-Franco P-J., Tábi T., Valadez-Gonzalez A.: Using factorial design methodology to assess PLA-g-Ma and henequen microfibrillated cellulose content on the mechanical properties of poly(lactic acid) composites. International Journal of Polymer Science, 2017, 4046862/1-4046862/14 (2017). https://doi.org/10.1155/2017/4046862

[9] Zhu J., Xue L., Wei W., Mu C., Jiang M., Zhou Z.: Modification of lignin with silane coupling agent to improve the interface of poly(L-lactic) acid/lignin composites. BioResources, 10, 4315-4325 (2015).

https://doi.org/10.15376/biores.10.3.4315-4325

[10] Petchwattana N., Channuan W., Naknaen P., Narupai B.: 3D printing filaments prepared from modified poly (lactic acid)/teak wood flour composites: An investigation on the particle size effects and silane coupling agent compatibilisation. Journal of Physical Science, 30, 169188 (2019).

https://doi.org/10.21315/jps2019.30.2.10

[11] Battegazzore D., Frache A., Abt T., Maspoch M. L.: Epoxy coupling agent for PLA and PHB copolymerbased cotton fabric bio-composites. Composites Part B: Engineering, 148, 188-197 (2018). https://doi.org/10.1016/j.compositesb.2018.04.055

[12] Nagarajan V., Mohanty A-K., Misra M.: Blends of polylactic acid with thermoplastic copolyester elastomer: Effect of functionalized terpolymer type on reactive toughening. Polymer Engineering and Science, 58, 280-290 (2018).

https://doi.org/10.1002/pen.24566 
[13] Zhang C., Wang W., Huang Y., Pan Y., Jiang L., Dan Y., Luo Y., Peng Z.: Thermal, mechanical and rheological properties of polylactide toughened by expoxidized natural rubber. Materials and Design, 45, 198-205 (2013). https://doi.org/10.1016/j.matdes.2012.09.024

[14] Meng B., Deng J., Liu Q., Wu Z., Yang W.: Transparent and ductile poly(lactic acid)/poly(butyl acrylate) (PBA) blends: Structure and properties. European Polymer Journal, 48, 127-135 (2012).

https://doi.org/10.1016/j.eurpolymj.2011.10.009

[15] Petchwattana N., Covavisaruch S., Euapanthasate N.: Utilization of ultrafine acrylate rubber particles as a toughening agent for poly(lactic acid). Materials Science and Engineering: A, 532, 64-70 (2012). https://doi.org/10.1016/j.msea.2011.10.063

[16] Saeed U., Nawaz M-A., Al-Turaif H-A.: Wood flour reinforced biodegradable PBS/PLA composites. Journal of Composite Materials, 52, 2641-2650 (2018).

https://doi.org/10.1177/0021998317752227

[17] Battegazzore D., Bocchini S., Frache A.: Crystallization kinetics of poly(lactic acid)-talc composites. Express Polymer Letters, 5, 849-858 (2011). https://doi.org/10.3144/expresspolymlett.2011.84

[18] Yang Y., Zhang L., Xiong Z., Tang Z., Zhang R., Zhu J.: Research progress in the heat resistance, toughening and filling modification of PLA. Science China Chemistry, 59, 1355-1368 (2016). https://doi.org/10.1007/s11426-016-0222-7

[19] Kim H-S., Park B-H., Choi J-H., Yoon J-S.: Mechanical properties and thermal stability of poly(L-lactide)/calcium carbonate composites. Journal of Applied Polymer Science, 109, 3087-3092 (2008).

https://doi.org/10.1002/app.28229

[20] Nagarajan V., Mohanty A. K., Misra M.: Perspective on polylactic acid (PLA) based sustainable materials for durable applications: Focus on toughness and heat resistance. ACS Sustainable Chemistry and Engineering, 4, 2899-2916 (2016).

https://doi.org/10.1021/acssuschemeng.6b00321

[21] Jiang L., Zhang J., Wolcott M-P.: Comparison of polylactide/nano-sized calcium carbonate and polylactide/ montmorillonite composites: Reinforcing effects and toughening mechanisms. Polymer, 48, 7632-7644 (2007). https://doi.org/10.1016/j.polymer.2007.11.001

[22] Osman M-A., Atallah A., Suter U-W.: Influence of excessive filler coating on the tensile properties of LDPEcalcium carbonate composites. Polymer, 45, 1177-1183 (2004).

https://doi.org/10.1016/j.polymer.2003.12.020

[23] Fuentes C-A., Brughmans G., Tran L. Q. N., DupontGillain C., Verpoest I., van Vuure A-W.: Mechanical behaviour and practical adhesion at a bamboo composite interface: Physical adhesion and mechanical interlocking. Composites Science and Technology, 109, 40-47 (2015).

https://doi.org/10.1016/j.compscitech.2015.01.013
[24] Battegazzore D., Abt T., Maspoch M. L., Frache A.: Multilayer cotton fabric bio-composites based on PLA and PHB copolymer for industrial load carrying applications. Composites Part B: Engineering, 163, 761-768 (2019).

https://doi.org/10.1016/j.compositesb.2019.01.057

[25] Akbari A., Jawaid M., Hassan A., Balakrishnan H.: Epoxidized natural rubber toughened polylactic acid/ talc composites: Mechanical, thermal, and morphological properties. Journal of Composite Materials, 48, 769-781 (2014).

https://doi.org/10.1177/0021998313477461

[26] Battegazzore D., Bocchini S., Alongi J., Frache A.: Rice husk as bio-source of silica: Preparation and characterization of PLA-silica bio-composites. RSC Advances, 4, 54703-54712 (2014). https://doi.org/10.1039/C4RA05991C

[27] Kang K. S., Lee S. I., Lee T. J., Narayan R., Shin B. Y.: Effect of biobased and biodegradable nucleating agent on the isothermal crystallization of poly(lactic acid). Korean Journal of Chemical Engineering, 25, 599-608 (2008).

https://doi.org/10.1007/s11814-008-0101-7

[28] Xu W., He P.: Isothermal crystallization behavior of polyoxymethylene with and without nucleating agents. Journal of Applied Polymer Science, 80, 304-310 (2001).

https://doi.org/10.1002/10974628(20010411)80:2<304::AID-APP1100>3.0.CO;2-N

[29] Alata H., Hexig B., Inoue Y.: Effect of poly(vinyl alcohol) fine particles as a novel biodegradable nucleating agent on the crystallization of poly(3-hydroxybutyrate). Journal of Polymer Science Part B: Polymer Physics, 44, 1813-1820 (2006).

https://doi.org/10.1002/polb.20846

[30] Kawamoto N., Sakai A., Horikoshi T., Urushihara T., Tobita E.: Nucleating agent for poly(L-lactic acid) - An optimization of chemical structure of hydrazide compound for advanced nucleation ability. Journal of Applied Polymer Science, 103, 198-203 (2007).

https://doi.org/10.1002/app.25109

[31] Samthong C., Kunanusont N., Deetuam C., Wongkhan T., Supannasud T., Somwangthanaroj A.: Effect of acrylonitrile content of acrylonitrile butadiene rubber on mechanical and thermal properties of dynamically vulcanized poly(lactic acid) blends. Polymer International, 68, 2004-2016 (2019). https://doi.org/10.1002/pi.5912

[32] Liang J-Z., Zhou L., Tang C-Y., Tsui C-P.: Crystalline properties of poly(L-lactic acid) composites filled with nanometer calcium carbonate. Composites Part B: Engineering, 45, 1646-1650 (2013).

https://doi.org/10.1016/j.compositesb.2012.09.086

[33] Petchwattana N., Covavisaruch S., Petthai S.: Influence of talc particle size and content on crystallization behavior, mechanical properties and morphology of poly (lactic acid). Polymer Bulletin, 71, 1947-1959 (2014). https://doi.org/10.1007/s00289-014-1165-7 
[34] Murariu M., Dubois P.: PLA composites: From production to properties. Advanced Drug Delivery Reviews, 107, 17-46 (2016).

https://doi.org/10.1016/j.addr.2016.04.003

[35] Petchwattana N., Narupai B.: Synergistic effect of talc and titanium dioxide on poly(lactic acid) crystallization: An investigation on the injection molding cycle time reduction. Journal of Polymers and the Environment, 27, 837-7846 (2019).

https://doi.org/10.1007/s10924-019-01396-0
[36] Xia X., Shi X., Liu W., Zhao H., Li H., Zhang Y.: Effect of flax fiber content on polylactic acid (PLA) crystallization in PLA/flax fiber composites. Iranian Polymer Journal, 26, 693-702 (2017). https://doi.org/10.1007/s13726-017-0554-9

[37] Gao X., Liu R., Jin M., Bu H.: Crystallization and morphology of poly(ethylene-2,6-naphthalene dicarboxylate) in the presence of nucleating agents. Journal of Polymer Science Part B: Polymer Physics, 40, 23872394 (2002).

https://doi.org/10.1002/polb.10296 